\title{
Performances de gênero: masculinidades no cinema a partir de dois filmes latino-americanos - Boi neon (2015) e Fango (2012) ${ }^{1}$
}

\author{
'Performances' de género: masculinidades en el cine a partir de dos \\ películas latinoameticanas - 'Boi noen' (2015) e 'Fango' (2012)
}

\section{Gender performances: masculinities in the cinema from two Latin- American films - Boi noen (2015) e Fango (2012)}

\author{
Joelma Ferreira dos Santos ${ }^{2}$
}

\begin{abstract}
Resumo
As obras cinematográficas, como outras formas de expressão artística, constituem locus privilegiado para colocar em relevo aspectos da sociedade que são transformados em temas incômodos ou passíveis de ser invisibilizados pelos setores conservadores em determinados contextos históricos. É o caso, por exemplo, das múltiplas formas de "performar" o gênero ou ainda de exercer a sexualidade. Tema de grande relevância na atualidade, a relação sexo/gênero, assim como seu caráter biológico ou cultural, desperta debates calorosos, mas também conflitos e disputas ideológicas importantes, sobretudo nos últimos anos. O presente trabalho é fruto da análise preliminar de dois filmes latino-americanos da atualidade, cujas abordagens trazem pontos de reflexão acerca das representações de gênero. O objetivo principal é discutir, a partir dos filmes Boi neon (Direção Gabriel Mascaro, Brasil, 2015) e Fango (Direção José Celestino Campusano, Argentina, 2012), a relação sexo/sexualidade/gênero/identidade(s) através de personagens masculinos cujas performances se distanciam do perfil de masculinidade tradicional e de personagens femininos que "performam" masculinidades. Judith Butler (2002; 2003), Thomas Laqueur (2001), R. Connell (2015) e Joan Scott (1995), são os principais referenciais teóricos.
\end{abstract}

Palavras-Chave: gênero; masculinidades; cinema latino-americano; performance

\section{Resumen}

Las obras cinematográficas, como otras formas de expresión artística constituyen locus privilegiado para poner de relieve los aspectos sociales de la sociedad que son transformados en temas poco cómodos o que pueden ser invisibilizados por sectores conservadores en determinados contextos históricos. Es el caso, por ejemplo, de las múltiples maneras de performar el género o aún de diferente formas de ejercer la sexualidad. Tema de gran relevancia en la actualidad, la relación sexo/género, bien como su carácter biológico o cultural, despierta calurosos debates, pero también conflictos y disputas ideológicas importantes, sobretodo en los últimos años. El presente trabajo es fruto del análisis preliminar de dos películas latinoamericanas de la actualidad, cuyos abordajes sugieren puntos de reflexión sobre representaciones de género. El principal objetivo es debatir, a partir de las películas Boi neon (Dirección Gabriel Mascaro, Brasil, 2015) y Fango (Dirección José Celestino

\footnotetext{
${ }^{1}$ Artigo apresentado no Simpósio Temático ST 02 - Saberes de desaprendizagens, Artes, Gênero e Sexualidade, durante o II Seminário Latino-Americano de Estudos em Cultura - SEMLACult em Foz do Iguaçu/PR, Brasil, 2018.

2 Doutoranda; Programa de Pós Graduação em História da Universidade do Estado de Santa Catarina PPGH/UDESC; Florianópolis, Santa Catarina, Brasil; fsantos.joelma@gmail.com.
} 
Campusano, Argentina, 2012), la relación sexo/sexualidad/género/identidad(es) a través de personajes masculinos cuyos performances son lejanos del perfil de masculinidad tradicional y de personajes femininos que "performan" masculinidades. Judith Butler (2002; 2003), Thomas Laqueur (2001), R. Connell (2015) y Joan Scott (1995), son los principales referentes teóricos.

Palabras claves: género; masculinidades; cine latino-americano; performance

\begin{abstract}
Cinematographic works, like other forms of artistic expression, are a privileged locus for highlighting aspects of society that are transformed into taboo subjects or that can be invisibilized by conservative sectors in certain historical contexts. This is the case, for example, of the multiple ways of "performing" gender or even of exercising sexuality. Issue of great relevance nowadays, the sex / gender relationship, as well as its biological or cultural nature, arouses heated debates, but also conflicts and important ideological disputes, especially in recent years. The present work is the result of the preliminary analysis of two Latin American films of the present day, whose approaches bring some thoughts about the representations of gender. The main objective is to discuss from Boi neon (Director Gabriel Mascaro, Brasil, 2015) and Fango (Director José Celestino Campusano, Argentina, 2012), the relation between sex/sexuality/gender/identity(ies) through male characters whose performances deviate from the traditional masculinity profile and through female characters that "perform" masculinities. Judith Butler (2002; 2003), Thomas Laqueur (2001), R. Connell (2015) and Joan Scott (1995) are the main theoretical framework of this work.
\end{abstract}

Keywords: gender; masculinities, Latin-American cinema; performance

\title{
1. Introdução
}

Gênero e sexualidade são duas palavras que, definitivamente, retornaram ao centro dos debates, tomando dimensões que talvez não tenham precedentes na história. Desde o início deste século, com ênfase especial nos últimos anos da década em curso, o gênero passou a ser um conceito em torno do qual gravitam, por um lado, teóricas/os dos estudos feministas, profissionais da educação, sexólogas/os, militantes e outros membros progressistas da sociedade, e por outro, teólogos, padres, pastores (alguns dos quais convertidos em políticos) e demais grupos conservadores da comunidade em geral. Estes últimos, usando da estratégia do pânico moral, foram responsáveis por mudanças drásticas nos rumos da sociedade, não só no Brasil como nos demais países da América Latina ${ }^{3}$.

À medida que os estudos teóricos se aprofundaram na distinção entre sexo e gênero e, portanto, na percepção tanto da diversidade sexual quanto das identidades de gênero, foram despertando desconfiança nos setores mais conservadores dessas sociedades, os quais passaram a ver nessas teorias o sinal de uma suposta "ideologia" cuja finalidade seria a destruição da família - vale dizer, do único modelo reconhecido por eles. Ao mesmo tempo,

\footnotetext{
${ }^{3}$ Referimo-nos ao que se denominou, entre os grupos conservadores, de "ideologia de gênero". Ver BALIEIRO, 2018; MACHADO, 2018; MISKOLCI \& CAMPANA, 2017; ROSADO-NUNES, 2015, entre outros/as.
} 
os debates que foram sendo fomentados na sociedade pelos grupos conservadores dos vários países tendiam a atrelar - quando não a reduzir - o gênero às diferenças biológicas entre os sexos e defender a manutenção ou o retorno a ultrapassadas formas de divisão dos papeis sociais de gênero. $\mathrm{O}$ acirramento dessas ideias teve um de seus momentos mais lamentáveis em 2017, por ocasião da última visita de Judith Butler ao Brasil, quando a filósofa estadunidense foi hostilizada após sua participação em eventos na cidade de São Paulo ${ }^{4}$. A escolha de Butler como alvo de protestos guarda relação com a compreensão equivocada de sua abordagem sobre gênero. $\mathrm{O}$ fato de considerar os corpos em sua materialidade para desenvolver sua teoria da performatividade alimentou discursos de medo, os quais foram assimilados e traduzidos em expressões que não só refletem incompreensão dos conceitos como servem de combustível para o pânico moral.

Mas afinal, as diferentes identidades de gênero guardam relação com as designações biológicas do sexo ou mesmo com as formas de exercer a sexualidade? O sexo é determinante para a identidade de gênero? O que pode ser considerado "natural" e o que é histórico em meio a isso tudo? Como diferentes corpos sexuados são "dados a ler" (mostramse e são interpretados) enquanto pertencentes ou designados a um gênero por outros corpos igualmente generificados?

Tomando essas inquietações iniciais como pontos de partida e tendo os filmes Boi neon (Direção Gabriel Mascaro, Brasil, 2015) e Fango (Direção José Celestino Campusano, Argentina, 2012) como base para algumas indagações, busco perceber as representações de gênero presentes nesses filmes a partir do conceito de performatividade elaborada por Judith Butler (2003). Para tanto, retomo a discussão sobre a "invenção do sexo" como um evento científico entre os séculos XVIII e XIX, conforme proposto por Thomas Laqueur (2001), elemento significativo nas disputas de poder que, de acordo com Joan Scott (1995) e outras/os autoras/es, constituíram e constituem as relações de gênero e são parte importante da forma de hierarquização das mesmas.

\section{O sexo como "invenção" para ressignificar o gênero}

"Em alguma época do século XVIII, o sexo que nós conhecemos foi inventado". Com essa frase um tanto impactante Thomas Laqueur (2001, p. 189) inicia o quinto capítulo de sua

\footnotetext{
4 Ver https://www1.folha.uol.com.br/ilustrissima/2017/11/1936103-judith-butler-escreve-sobre-o-fantasma-dogenero-e-o-ataque-sofrido-no-brasil.shtml
} 
obra Inventando o sexo: corpo e gênero dos gregos a Freud. Uso o termo "impactante" aqui para ressaltar o caráter naturalizado do binarismo sexual que impregna nossa sociedade contemporânea e serve de fundamento para que grupos conservadores elaborem discursos de condenação da diversidade e fomentem o ódio e preconceito a qualquer conduta que se afaste da heteronormatividade. Entendido como um dado biológico concreto e a-histórico, portanto, o sexo tem servido também de base para a elaboração de práticas discursivas que procuram justificar as relações de poder estabelecidas com base no gênero, o que se faz sentir desde os contextos mais amplos, como no universo dos poderes políticos e econômicos, até as questões mais cotidianas, como, por exemplo, as relações familiares. Como observa Joan Scott entre outras/os, as relações de gênero são perpassadas pelas relações de poder, em verdade, "o gênero é uma forma primária de dar significado às relações de poder" (SCOTT, 1995, p 86).

O que Laqueur procura fazer ao longo de sua obra é desconstruir esse caráter natural atribuído ao sexo, demonstrando como, de certa maneira, o cientificismo dos séculos XVIII e XIX construiu discursivamente o binarismo sexual, ao ressaltar as diferenças anatômicas de maneira que elas pudessem justificar de forma mais "fundamentada" as diferenças de gênero que estavam sendo postas em questão naquele momento. Durante séculos o corpo das mulheres foi visto como um corpo masculino invertido. Alguns órgãos, como os ovários, eram identificados como testículos femininos e o ventre (somente chamado de útero a partir desse período) era uma espécie de falo negativo. O corpo feminino era considerado uma versão imperfeita do masculino, "uma vez que lhe faltava o calor vital, retido no seu interior" (FLORES, 2005, p. 55). Desde essas considerações, é possível dizer que não só o gênero, tal como está posto hoje, é fruto de uma construção social que buscou organizar a sociedade em termos hierárquicos, como o próprio binarismo sexual também foi construído cultural e cientificamente no sentido de reforçar as diferenças entre os gêneros.

Quando, por várias razões, a ordem transcendental preexistente ou os costumes de tempos imemoriais tornaram-se cada vez menos uma justificativa plausível para as relações sociais, o campo de batalha do gênero mudou para a natureza, para o sexo biológico. A anatomia sexual distinta era citada para apoiar ou negar todas as formas de reivindicações em uma variedade de contextos sociais, econômicos, políticos, culturais e eróticos. (...) Qualquer que fosse o assunto, o corpo tornou-se o ponto decisivo (LAQUEUR, 2001, p. 192).

Ou seja, a partir da noção dos gêneros masculino e feminino se construiu uma normatização dos sexos associando-os a comportamentos e a papeis sociais específicos, consequentemente, a uma heterossexualidade normativa. Dessa maneira, diversas formas de se exercer a sexualidade passaram a ser marginalizadas, assim como identidades de gênero diversas foram ignoradas ou vistas como "anomalias" por não caberem na caixinha 
normatizada sexo/gênero. Como decorrência, espera-se que cada corpo sexuado tenha uma "performance" que corresponda ao que culturalmente se construiu como o gênero correspondente a determinado sexo.

\section{Gênero como performance}

Não é exagero dizer que o estopim para a efervescência dos debates em torno das questões de gênero que vivemos hoje foi aceso pelos movimentos da chamada segunda onda do feminismo e dos grupos LGBT, os quais remontam aos anos 70 do século passado. É certo que as diferenças culturais entre homens e mulheres foram se desenvolvendo desde tempos imemoriais, como vimos anteriormente, e a utilização destas diferenças como elemento de subordinação das mulheres contou, há séculos, com todo um aparato discursivo que foi desde a Religião, passando pela Medicina, Direito, Filosofia, Sociologia e Política, entre outras áreas, produzindo "verdades fundadoras" que justificassem o domínio masculino (FLORES, 2005, p. 52). Mas é inegável que as querelas em torno das questões de gênero ganharam mais força nas últimas décadas tanto em função das diferentes abordagens dos feminismos como do ativismo LGBT.

Embora a separação sexo/gênero em categorias distintas de análise que muitas feministas adotaram ao longo das décadas que se seguiram à segunda onda feminista tenha ocasionado, em alguns casos, a essencialização do sexo, consequentemente da mulher (SCOTT, 1995, p. 83-84), essas estratégias foram importantes para abrir diferentes caminhos de teorização das relações de gênero. Ademais, e como observa Joana Maria Pedro (2005, p. 90-91), “apesar da afirmação de que se tratava de coisas diferentes, era sobre o sexo biológico que se estava constituindo a identidade de gênero, e no caso dos integrantes dos movimentos gays e lésbicos, estes termos não coincidiam”.

Esse impasse foi encarado e analisado em profundidade por Judith Butler através do que ela considerou um problema de gênero, o que, aliás, serviu de título para uma de suas obras mais importantes. "Ser mulher constituiria um 'fato natural' ou uma performance cultural, ou seria a 'naturalidade' constituída mediante atos performativos discursivamente compelidos, que produzem o corpo no interior das categorias de sexo e por meio delas?" (BUTLER, 2003, p. 8-9). Esta é uma das várias perguntas que a autora coloca como ponto de partida em Problemas de Gênero. Ela propõe uma série de indagações através das quais não somente problematiza o caráter de uma essência feminina que constituiria o ser mulher 
enquanto sexo biológico, como considera essa questão central para pensar outros aspectos fundamentais como as identidades dos sujeitos.

Nesse sentido, e como observa Joana Pedro, os movimentos gays e lésbicos, foram fundamentais para colocar em relevo determinados pontos que são essenciais para o processo de teorização acerca da performatividade. Butler (2003, p. 8) indaga-se: "Seria o drag uma imitação de gênero, ou dramatizaria os gestos significantes mediante os quais o gênero se estabelece?". Em Cuerpos que importan (2002), sobretudo no capítulo em que analisa o filme documentário Paris está em chamas (Paris is Burning, dir. Jennie Livingston, EUA, 1990), a filósofa considera os diversos personagens - homens homossexuais que se travestem tanto de mulheres como de homens heterossexuais em bailes promovidos por eles próprios no Harlem, Nova York, nos anos 80 - para ir a fundo nesta questão dos atos performativos como discursos construídos sobre os gêneros.

Nesta obra, a autora procura aprofundar e esclarecer alguns pontos relativos ao livro anterior $^{5}$, no qual desenvolve as linhas gerais de sua "teoria da performatividade". Butler parte da noção altusseriana de interpelação e de poder da lei (a partir das contribuições de Lacan) como elementos importantes na constituição do sujeito social para problematizar a relação sexo/gênero e, a partir daí, questionar o caráter de subversão ou de apropriação do gênero que se dá no ato do travestismo (drag). Discute, pois, o caráter constitutivo do "eu" como um lugar de encruzilhada (crossroads) de forças discursivas culturais e políticas capazes de romper inclusive com a própria noção de sujeito. Para ela, “el travestismo es subversivo por cuanto se refleja en la estructura imitativa mediante la cual se produce el género hegemónico y por cuanto desafía la pretensión a la naturalidad y origínalidad de la heterosexualidad" (BUTLER, 2002, p. 185).

Judith Butler, autora que foi fortemente influenciada Michel Foucault, entre outros nomes igualmente importantes, ao questionar a relação sexo biológico-corpo sexuadogênero-performance de gênero, fornece uma enorme contribuição para que possamos avançar no sentido de perceber as relações de gênero com um olhar cada vez menos normatizado. Contudo, embora sua teoria seja majoritariamente ancorada na performatividade dos travestis e drags, tal concepção não se limita a eles. Para Butler, o sexo também é revestido de historicidade e o gênero é performativo, independente do sexo ou da orientação sexual. Mesmo a heterossexualidade é um ato performativo. E é nesse sentido, de performance como

\footnotetext{
${ }^{5}$ Como utilizo uma tradução em português e outra em espanhol, há uma diferença de datas em relação às publicações originais. Assim, Problemas de Gênero (2003) é anterior a Cuerpos que importam (2002) em suas versões originais.
} 
elemento de discursividade sobre os gêneros, que analisamos as películas argentina e brasileira anteriormente mencionadas.

\section{Performances de gênero em Boi neon (2015) e Fango (2012)}

Entre a grande variedade de artefatos culturais que contribuíram para criar ou reforçar estereótipos de gênero, o cinema ocupa um lugar privilegiado. Tanto o hollywoodiano - que, através do "american life way" propagado em seus filmes ao longo de quase um século, leva seus padrões sociais mundo afora - como também as filmografias nacionais na América Latina. Nos Estados Unidos, por exemplo, o western, foi o gênero responsável pelo desenvolvimento de um modelo de hombridade ou um padrão de masculinidade, o macho valentão do "velho oeste". No México, por sua vez, a comédia ranchera produziu o charro, o qual inspirou o modelo de masculinidade latino-americana (DIAZ LÓPEZ, 1999). Através dos melodramas latino-americanos, o cinema também serviu como educador sentimental das mulheres dentro dos padrões da moral judaico-cristã (OROZ, 1999) e sugeriu a imagem ideal destas nas relações sociais e conjugais (TUÑON, 1998).

É fato que a centralidade ocupada nesse sentido já não é a mesma de antes, sobretudo se pensarmos em termos de recepção, posto que o cinema divide a atenção do público com uma infinidade de outras mídias. Contudo, continua sendo um produto cultural importante para análise das representações e é nesse sentido que recorro a essas fontes.

Argentina e Brasil são países cujas histórias nacionais têm pontos de distanciamento considerável, mas também muitos aspectos em comum. E uma das convergências é uma produção cinematográfica reconhecida internacionalmente por sua qualidade técnica, mas, principalmente, pela abordagem atenta às transformações e peculiaridades das sociedades em questão. Embora tenha consciência de que os dois filmes escolhidos para análise, neste trabalho, não são representativos do conjunto de obras produzidas nos últimos anos nesses dois países, são interessantes devido à forma como abordam as relações e identidades de gênero, constituindo-se importantes textos culturais (BUTLER, 2002) que podem ser lidos à luz dos recentes debates sobre gênero. E o que nos dizem esses textos? Quais reflexões podem ser feitas a partir deles? Para além da orientação sexual e das identidades de gênero, o que há de elementos discursivos nesses sujeitos?

Boi neon (Brasil, 2015), dirigido pelo cineasta e artista visual Gabriel Mascaro, aborda o dia a dia de um grupo de "curraleiros", como são chamados os tratadores dos animais que serão soltos nas arenas de vaquejada pelo interior do nordeste brasileiro. A peculiaridade dos 
personagens de Boi neon reside no fato de romperem com alguns estereótipos de gênero. Tanto Iremar (Juliano Cazarré) como Júnior (Vinícius de Oliveira), personagens masculinos (homens cisgêneros), performam masculinidades que têm alguns elementos de convencionalidade (orientação heterossexual, vestimenta, linguagem, postura corporal, etc.) e outros que são conflitantes com a discursividade sobre os homens heterossexuais no interior do nordeste brasileiro. Iremar, embora execute a função de curraleiro com aparente maestria, ocupa suas horas vagas com atividades relacionadas com a moda: desenha, corta e costura roupas para apresentações nas vaquejadas. A masculinidade de Júnior, outro vaqueiro incorporado ao grupo, também foge da convencionalidade. Passa parte de seu tempo ocioso alisando, com prancha quente, seus longos e crespos cabelos, e os "ajeita" com gestos suaves, normalmente associados ao feminino.

As maneiras como Iremar e Júnior performam suas masculinidades não causam perplexidade nos demais personagens masculinos e nem mesmo nos femininos. Não têm suas masculinidades questionadas pelas mulheres com as quais se relacionam. Somente Zé (Carlos Pessoa), que representa a chamada mascunilidade tradicional (entendida como aquela que encarna o estereótipo do macho), em momento de descontração, refere-se ao gosto de Iremar pela moda como uma velha caduca de agulha na mão, costurando. Mas este comentário tem o mesmo peso do que Iremar faz, a modo de revide, ao dizer que Zé tira a roupa quando bebe. Esse diálogo rápido e aparentemente engraçado na hora do almoço remete às reflexões feitas por Butler (2003) acerca da construção do gênero enquanto elemento de discursividade e sobre a vigilância que se exerce sobre a heterossexualidade.

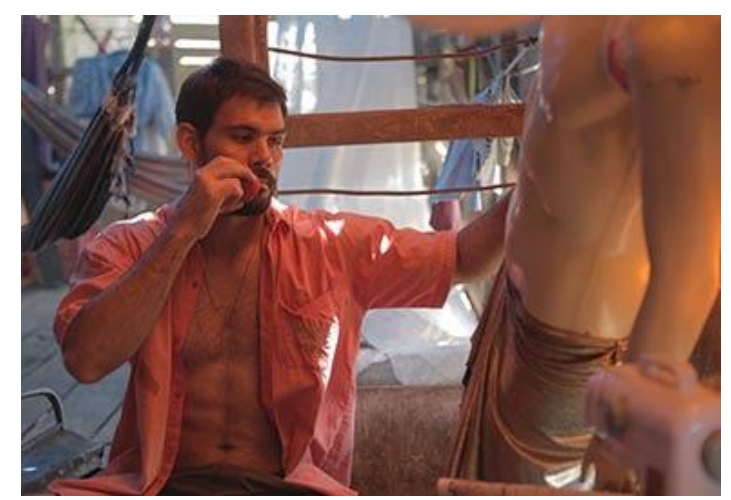

Figura 1 - Iremar (Boi neon, 2015)

Fonte: www.boinneon.com.br

Da mesma forma, também em Boi neon, Galega (Maeve Jinkings), mulher cis e heterossexual, não encarna um estereótipo de feminilidade. É uma personagem cuja performance de gênero é tão complexa quanto a de Iremar. Responsável por dirigir o 
caminhão que transporta bois e trabalhadores para eventos e serve de casa improvisada em cada parada, ela "atua" tanto como mecânica do caminhão, como dançarina sensual nos bailes da vaquejada. Ao mesmo tempo que está preocupada com uma estética associada à feminilidade (depilação e calcinhas sexys), veste-se sempre com short, camiseta e tênis e recebe críticas dos vaqueiros por sua atuação como mãe da menina Cacá (Alyne Santana), sem que isso lhe cause qualquer sentimento de culpa ou frustração. $O$ ambiente hostil do trabalho de Galega propicia certa fluidez na sua performance de gênero.

Com uma proposta totalmente diferente, o filme Fango (Argentina, 2012), dirigido por José Celestino Campusano, traz duas histórias paralelas, as quais se passam nos subúrbios de Buenos Aires: por um lado as desventuras del Brujo (Oscar Génova) e del Indio (Claudio Miño), dois músicos de heavy metal que procuram montar uma banda de tango trash; e por outro, a de Nadia (Nadia Batista) que, a pedido de sua prima, resolve dar uma "lição" em Beatriz (Olga Obregón), a mulher del Brujo que tem um caso extraconjugal com o marido da prima. Para o tema do qual me ocupo aqui, é a história de Nadia que interessa mais diretamente.

Pensar as masculinidades implica em questionar o que significa ser homem (DE LA MORA, 2006). Isto torna praticamente impossível ou inoperante a busca de uma definição, já que se trata de algo que é não estático, ou seja, muda de acordo com o tempo e varia conforme o espaço. Tal opinião é compartilhada por Redondo (2003), que também percebe a noção de masculinidade como muito ampla, ambígua e histórica para ser fixada num conceito estático e imutável.

Connell, por sua vez, ressalta que masculinidade é um conceito "inerentemente relacional" e que não existe fora da oposição à feminidade. Por isso afirma que, até onde o termo pode ser definido, "es un lugar en las relaciones de género, en las prácticas a través de las cuales los hombres y las mujeres ocupan este espacio en el género, en los efectos de dichas prácticas sobre la experiência corporal, la personalidade y la cultura" (2015, p. 106). Nesse sentido, as masculinidades são pensadas como características inerentes aos homens, sejam eles cis ou transgêneros.

Contudo, como foi abordado inicialmente, se entendemos o gênero como elemento de discursividade, conforme proposto por Butler, tanto Nadia como as suas amigas que se propõem a ajudá-la na tarefa de sequestrar Beatriz são mulheres cis (dentre as quais algumas se afirmam homossexuais) e performam masculinidades. Ao assumir para si a tarefa de afastar Beatriz do marido de sua prima, Nadia incorpora atitudes atribuídas ao gênero masculino: 
aliado aos elementos estéticos como postura corporal, roupas, fala e forma de movimentar-se nos espaços da cidade, seu estilo agressivo é o mais destacado dentre os elementos associados às masculinidades. Agressões físicas, sequestro, abuso sexual, uso de armas de fogo e assassinatos fazem parte do repertório de violências que pratica com suas amigas. A cena em que Nadia abusa sexualmente de Beatriz, cujas mãos e pés estão presos à cama por correntes, é bastante ilustrativa. Sua intenção é demonstrar poder também no plano sexual.

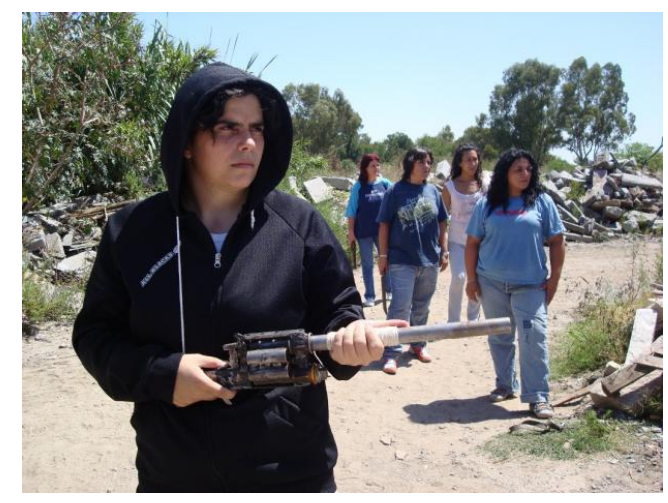

Figura 2 - Nadia (Fango, 2012)

Fonte: www.cinenacional.com

Pensar o gênero enquanto performance contribui para a desnaturalização da associação automática sexo masculino/gênero masculino, sexo feminino/gênero feminino, sobretudo dentro de uma matriz heteronormativa que vincula outras formas de construção de subjetividades a condutas "desviantes". Há, como ressalta Butler, uma gama bastante ampla de possibilidades de identidades.

É importante ressaltar também que, embora o conceito de performatividade em Butler seja desenvolvido e exemplificado a partir do comportamento de travestis, drags e transgêneros, não se trata, a meu ver, de um conceito limitador, cuja aplicabilidade seja unicamente para os atos performativos mais explícitos. Encarar o gênero como uma forma de discursividade abre espaço para a multiplicidade de subjetividades que caracteriza os sujeitos, como pode ser observado, sobretudo nos personagens de Boi neon, mas também em Fango.

Os filmes não são espelhos das sociedades, são produtos culturais que trazem a possibilidade de reflexões sobre elas, porque se inspiram nelas. Nesse sentido, talvez eles possam, através da diversidade de abordagens que os caracteriza, contribuir para a percepção de outras formas de subjetividade. Afinal, elas já estão postas.

\section{Referências}


BUTLER, Judith. El género en llamas: cuestiones de apropiación y subversión. In:

Cuerpos que importam: sobre los límites materiales y discursivos del "sexo". Trad. para o espanhol Alcira Bixio. Buenos Aires, Paidós, 2002.

. Problemas de gênero: feminismo e subversão da identidade. Trad. Renato Aguiar. Rio de Janeiro: Civilização Brasileira, 2003.

CONNELL, Raewyn. La organización social de la masculinidad. In: Masculinidades. Trad (para espanhol) Irene Artigas e Isabel Vericat. México DF: UNAM/PUEG, 2015.

DE LA MORA, Sergio. Introduction. Macho Nation?. In: Cinemachismo: masculinities and sexuality in mexican film. Austin: University Texas Press, 2006.

DÍAZ LÓPEZ, Marina. Jalisco nunca pierde: raíces y composición de la comedia ranchera como género popular mexicano. In: ELENA, Alberto \& PARANAGUÁ, Paulo (eds.). Mitologías Latinoamericanas, Archivos de la Filmoteca Valenciana, no 31, fevereiro, pp. 184197, 1999.

FLORES, Maria B. Ramos. O pensamento antifeminista e a querela dos sexos. In: Faces de Eva - Estudos sobre a mulher, n. 14. Lisboa: Universidade de Nova Lisboa: Edições Colibri, 2005. p. 51-74.

LAQUEUR, Thomas. A descoberta dos sexos. In: Inventando o sexo: corpo e gênero dos gregos a Freud. Trad. Vera Whately. Rio de Janeiro: Relume Dumará, 2001.

MACHADO, Maria das Dores Campos. O discurso cristão sobre a "ideologia de gênero". Estudos Feministas, v. 26, n. 2, p. 1-18, 2018.

MISKOLCI, Richard; CAMPANA, Maximiliano. "Ideologia de gênero": notas para a genealogia de um pânico moral contemporâneo. Sociedade e Estado, v. 32, n. 3, p. 725-747, 2017.

OROZ, Silvia. Melodrama: o cinema de lágrimas da América Latina Rio de Janeiro: Funarte, 1999.

PEDRO, Joana Maria. Traduzindo o debate: o uso da categoria gênero na pesquisa histórica. Revista História, v. 24, n.1, p. 77-98, 2005.

REDONDO, Raúl Iturra. La construcción social de la masculinidade. In: DEL RÍO, José M. V. y LÓPEZ. Juan Blanco (Editores). Hombres: la construcción cultural de las masculinidades. Madrid: Talasa Ediciones S.L, 2003

ROSADO-NUNES, Maria José Fontelas. A "ideologia de gênero" na discussão do PNE. A intervenção da hierarquia católica. HORIZONTE-Revista de Estudos de Teologia e Ciências da Religião, v. 13, n. 39, p. 1237-1260, 2015. 
SCOTT, Joan W. Gênero: uma categoria útil de análise histórica. Educação \& Realidade. Porto Alegre, vol. 20, no 2, jul./dez. 1995, pp. 71-99.

TUÑON, Julia Mujeres de luz y sombra en el cine mexicano: la construcción de una imagen, 1939-1952. México: El Colegio de México, Programa Interdisciplinario de Estudios de la Mujer e Instituto Mexicano de Cinematografía, 1998. 